\title{
THE REVITALIZATION OF RADAR SYSTEM AS A CASE OF FUNCTIONAL AND INFORMATION SECURITY PROBLEMS
}

doi: $\quad 10.2478 /$ czoto-2019-0088

Date of submission of the article to the Editor: $26 / 11 / 2018$

Date of acceptance of the article by the Editor: 18/01/2019

Dariusz Karpisz ${ }^{1}$ - orcid id: 0000-0002-2021-9726

Anna Kiełbus ${ }^{1}$ - orcid id: 0000-0001-7189-8901

${ }^{1}$ Cracow University of Technology, Poland, kielbus@mech.pk.edu.pl

\begin{abstract}
The paper presents selected problems of design of machinery retrofit in Industry 4.0 era. In order to show the diversity of applications of new technological achievements, the case of radar revitalization as a museum exhibit has been shown. Ensuring functional safety and staff work safety has been changed into the safety of visitors to the museum and bystanders. Different approaches to the implementation of the safe stop function in both the internal adjustable frequency drive and the safety terrain zone are presented in the article.
\end{abstract}

Keywords: industry 4.0, machinery retrofit, radar system, safety

\section{INTRODUCTION}

Nowadays, the term Industry 4.0 is entrenched in various areas of life. It involves achieving maximum benefits through the use of such acquisitions of Information and Communication Technologies (ICT) (US Access Board, 2015) as Internet or (Industrial) Internet of Things (IloT) (Misra et al., 2017). The basic problem is the lack of understanding of the subject of security by current designers as well as industrial automation of the Industry 3.0 era. Classical IT designers and programmers who are well-versed in the field of computer network security (Ghorbani et al., 2010), however, lack knowledge in the field of mechanics, electronics, automation and industrial networks. One of the new challenges is to adapt the machines currently used in industry to the requirements of working in an industrial network with new hazards (Colbert and Hutchinson, 2016). Retrofit can refer to both machine and control construction. This is especially so in the case of new control systems created for old machines where special attention should be paid in ensuring an adequate level of functional safety and network security.

When analyzing the issues of functional safety and security in the field of ICT in the implementation of industrial projects, the safety of work, process and product should be taken into account (Cierniak-Emerych et al., 2017).

In the presented case study, work safety has been redefined for the safety of museum visitors. The authors have worked on the concept of revitalization of the airport radar system (without a wave transmitter mounted) as a museum display unit mounted 
outside in the public space as shown in Fig. 1. This is an example of partial use of a mechanical device with its adaptation to perform a new function in new environmental conditions.

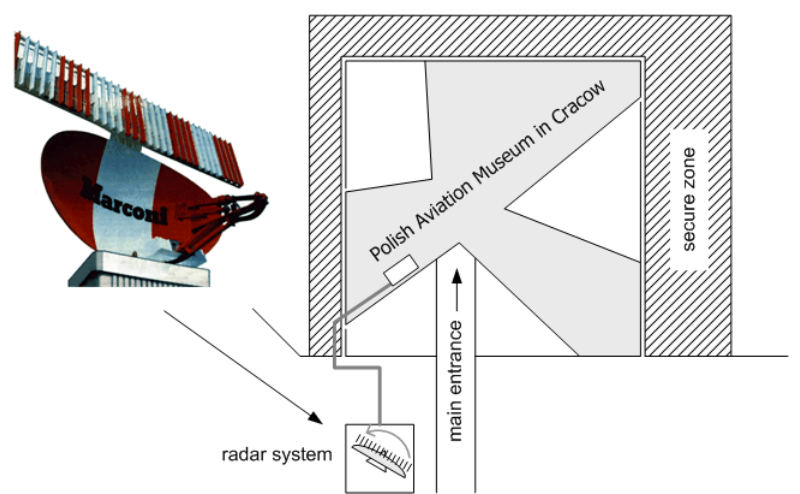

Fig. 1. Location of radar system (photo: The Controller, IFATCA, June 1985, pp.13)

Both the new use of radar and new functionality define different problems and risks. Airport radar devices should ensure reliable operation, and the device is mounted in a safe zone without access by unauthorized persons. The change of functionality as a museum exhibit makes human security the most important and reliability ceases to be crucial. In particular, the new control system must implement many restrictive standards dedicated to the industries where employees can have contact with machines with moving parts e.g. EN/ISO 13850.

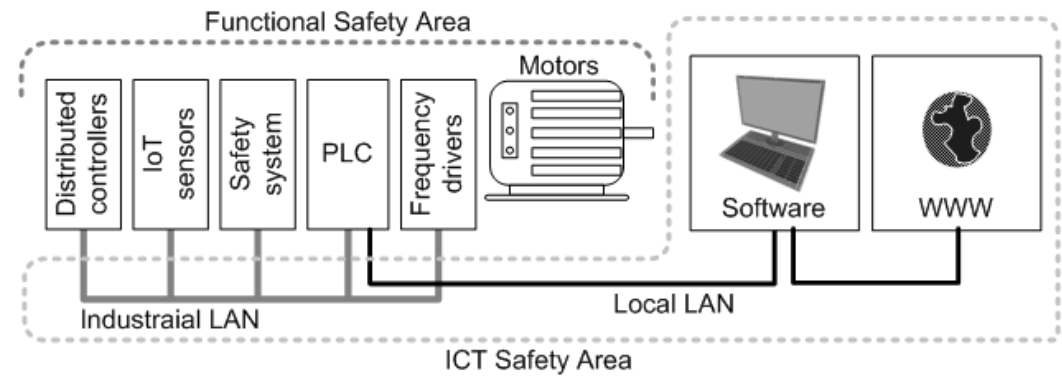

Fig. 2. Basic areas of functional and ICT security

The example presented in Fig. 2 highlights the problem of the separation of activities in the area of Functional Safety and ICT security. Functional Safety refer to the electromechanical part of machines and devices and is well described by standards. ICT Safety for industry does not have identical well-described standards. As shown in Fig. 2, these two topics complement each other, which is why it is necessary to implement Intrusion Detection System / Intrusion Prevention System (IDS/IPS) (Ghorbani et al., 2010; Colbert and Hutchinson, 2016) solutions for the industrial network (industrial LAN).

\section{MATERIALS AND METHODS}

As part of the mutual cooperation between the Institute of Applied Informatics and the Polish Aviation Museum in Cracow, a concept for renewal and motorization of the airport radar was created. The primary element of the project is the Marconi Radar Systems radar set consisting of a mounting base with 2 electric motors and a master antenna - Airport Surveillance Radar (ASR) and Secondary Surveillance Radar 
antenna (SSR) (Lynn, 1987). The ASR antenna has a parabolic structure and dimensions less than $6 \mathrm{~m}$ wide, while the SSR antenna is placed above the primary radar survey and has a width of about $9 \mathrm{~m}$.

As well as the basic problems (as described in more detail in Table 1), by using the EN ISO 12100 standard, the following issues have been defined:

- bad technical condition of the drive parts and lack of spare parts,

- lack of any control system,

- the need to mount the radar outside the protected area of the museum in close proximity to the city park with $24 / 7$ access by outsiders.

Table 1

Examples of identified hazards and corrective actions

\begin{tabular}{|l|l|}
\hline Potential hazard & Action \\
\hline $\begin{array}{l}\text { Open area - exposure of bystanders to health } \\
\text { loss in the antenna rotation field }\end{array}$ & $\begin{array}{l}\text { Construction of a fence with a side that is } \\
\text { larger than the radius of the antenna }\end{array}$ \\
\hline $\begin{array}{l}\text { Possibility of the intruder intruding through } \\
\text { the fence during operation of the drive }\end{array}$ & $\begin{array}{l}\text { Installation of optical or microwave barriers } \\
\text { in the internal protection zone of antennas }\end{array}$ \\
\hline $\begin{array}{l}\text { Non-existent control and monitoring system } \\
\text { of the device }\end{array}$ & $\begin{array}{l}\text { Design and construction of a control system } \\
\text { based on modern PLC devices and Internet } \\
\text { communication protocols with the ability to } \\
\text { operate with IloT devices }\end{array}$ \\
\hline $\begin{array}{l}\text { The ability to inclination of the SSR antenna } \\
\text { by foreign objects - the action of vandals or } \\
\text { atmospheric factors }\end{array}$ & $\begin{array}{l}\text { Installation of IloT spatial position sensors } \\
\text { on rotary antenna }\end{array}$ \\
\hline $\begin{array}{l}\text { Control and monitoring from inside the } \\
\text { building and from the Internet - double control }\end{array}$ & $\begin{array}{l}\text { Implementation of the control algorithm with } \\
\text { the exclusive control blocking }\end{array}$ \\
\hline $\begin{array}{l}\text { Monitoring and control via a Internet remote } \\
\text { HMl }\end{array}$ & $\begin{array}{l}\text { Implementation of Intrusion Prevention } \\
\text { System }\end{array}$ \\
\hline Non-existent driver for electric engine & $\begin{array}{l}\text { Select adjustable frequency drive with Safe } \\
\text { Stop function }\end{array}$ \\
\hline
\end{tabular}

The radar mounting base has two redundant $A C$ motors of $5.5 \mathrm{~kW}$ and a rated nominal current of $11 \mathrm{~A}$ with motoreductors ensuring the $15 \mathrm{rpm}$ rotational speed of the antennas. In addition to the nominal factors, the most important matter was the choice of emergency stop solutions in the event of unauthorized persons entering the antenna motion zone in accordance with industry standards EN IEC 61800-5-21 and EN/ISO 13850 defining stop types as:

- Stop Category 0 - stopping by immediate removal of electrical power to the motors and then stopping of machine motion,

- Stop Category 1 - a controlled stopping of machine motion with electrical power to machine motors to achieve the stop and then removal electrical power,

- Stop Category 2 - a controlled stopping of machine motion with electrical power left available after stop of machine motion.

Analyzing the specifics of the Marconi ASR radar propulsion solution and the forecasted high inertia of the antenna, it was necessary to select an adjustable frequency drive with a reserve of a power for controlling the drive. It was also required to provide Safe Torque Off (STO) functionality as defined by EN IEC 61800-5-21 and Stop Category 0 as defined in EN 60204-12, known as Safe Stop. After further analyzing the needs and requirements, the adjustable frequency Danfoss VLT drive 
model FC302P7K5 ( $P=7.5 \mathrm{~kW}$ and $\mathrm{In}=16 \mathrm{~A})$ with integrated Safe Stop functionality was selected.

Due to uninterrupted rotary motion, devices type IloT with loT Hub in the radar mounting base were proposed as position sensors.

\section{RESULTS}

As elements of the project implementation, many activities are planned, such as:

1. Selection of the exact location of the radar and selection of the location of the control cabinet inside the building and the location of the control panel (START/STOP, Emergency-STOP, Emergency-RESET buttons).

2. Repair of mechanical parts including motoreductors and the radar main bearing.

3. Selection, design and assembly of new sensors for the motoreductors, rotary encoder and spatial position sensors of the antennas to detect anomalies.

4. Selection and design of a functional security system and a control system based on a PLC controller and a distributed input/output with Safe Mode module.

5. Design of a remote monitoring and control system including internal network security, software and others.

Selected Danfoss VLT drive is approved to be suitable for the fulfillment of many standards:

- Level SIL 2 capability according to IEC 61508 and IEC 61800-5-2 standards,

- Level SILCL 2 according to EN 62061,

- Performance Level "d" according to EN ISO 13849-1:2008 and

- Safety Category 3 according to EN ISO 13849-1.

This choice implements the requirements defined in accordance with EN ISO 12100 standard.

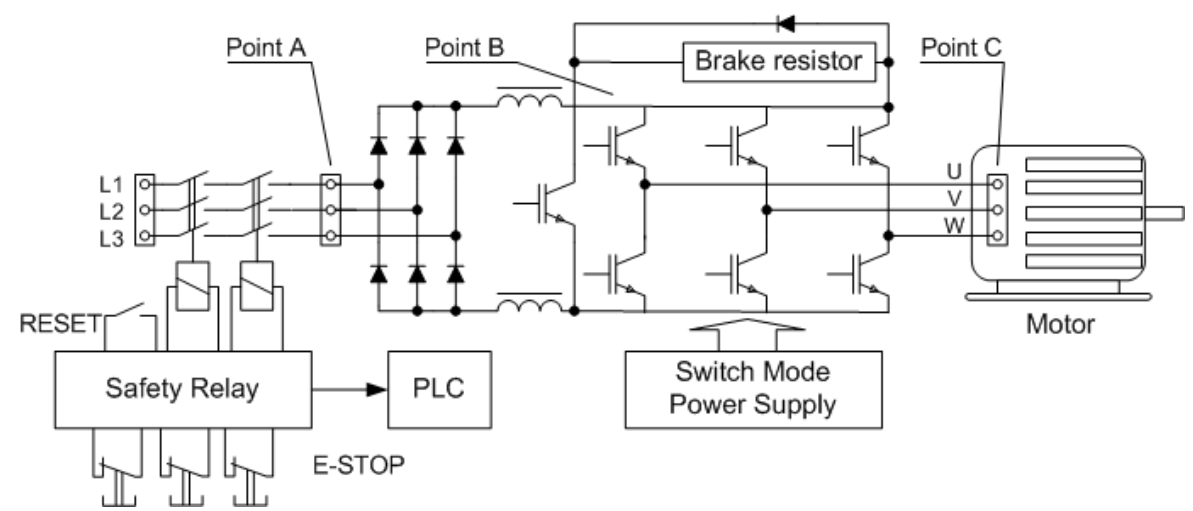

Fig. 3. Simplified, "classic" adjustable frequency drive layout with emergency power disconnection function

While selecting the available emergency stop solutions, possible solutions of the power off points for STO Category 0 were analyzed. As shown in Fig. 3, removal of electrical power can occur at the frequency driver input at point A. Information on the operation of protection in the form of a status change is also sent to the PLC. This solution ensures complete removal of dangerous voltage from the machine. However, it has disadvantages in the form of working on high voltage and high current values. The data from the frequency driver is also lost. In an emergency situation, it is also possible to immediately shut off the power source before the engine at point $\mathrm{C}$. 
However, this is not recommended and does not solve the problem of the lack of frequency driver monitoring.

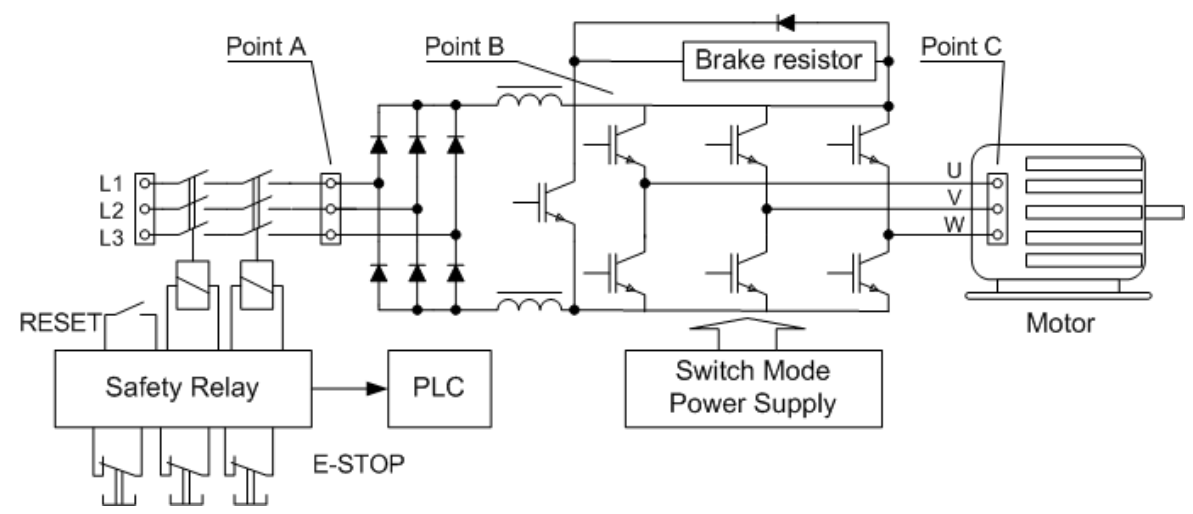

Fig. 4. Simplified adjustable frequency drive layout to implement selected Safe Torque Off function as monitored emergency stop

Modern adjustable frequency drives as proposed by Danfoss VLT series drive, have the ability to immediately cut off power by switching off in IGBT transistors marked as point B in fig. 4. Such solutions can use external safety relays or modules mounted inside the drive. There is no loss of communication between drive and PLC using dedicated digital I/O and industrial LAN over e.g. Profinet protocol.

The use of electromagnetic brake control (shown in Fig. 4) not used in the original is also available. Electromagnetic brake extend STO Category 0 function to control and speeding of stop machine movement.

In the area of ICT security, possible network threats were analysed and planned to be protected by continuous monitoring. It is planned to use encryption of communication in particular in the loT sensor operating in a wireless network in public space. Taking control of one sensor can permit control of the industry LAN and all connected devices.

\section{DISCUSSION}

The problem of device revitalization, especially if their functionality changes, requires re-analyzing functional and non-functional requirements. The example indicates a change from the system without functional protection to protection at SIL2 security level. The Machinery Directive (Directive 2006/42/EC, 2006) and current set of standards does not provide for many solutions such as multiplication of machine control panels or simultaneous access from WebHMl devices and classic control panels. The problem is the lack of awareness of the importance of securing even the simplest device such as a wireless distance sensor. loT era gives huge possibilities for monitoring devices with cable elimination, but at the same time significantly increases the risk of cyber hacking and taking control even over the entire factory. In the presented example, we can imagine a situation in which the hacker changes the values of the frequency drive factors and accelerates the radar to a speed that is dangerous for the integrity of the structure. The control concepts in the field of functional safety also change. The shift of the safety relay functionality to frequency drive provides better monitoring of the control system and increase the life of switching elements. The presented examples are only an introduction to the subject presented in the title. 


\section{POSSIBLE REUSABILITY}

Presented approach to the issue of a safety may be directly used in many other areas of activity, especially at large scale facilities with a huge infrastructure e.g. FAIR at Darmstadt (Singh et al., 2016a; Singh et al., 2016b; Singh et al., 2017), however it is still usable at smaller, but also potentially dangerous stands, industrial or research, e.g. hydraulic test stands (Lisowski and Filo, 2017; Krawczyk et al., 2018), biotechnological laboratories (Skrzypczak-Pietraszek and Pietraszek, 2009; Skrzypczak-Pietraszek et al., 2018) or chemical labs, especially with critically toxic heavy metals (Ulewicz et al., 2003; Ulewicz et al., 2007; Ulewicz et al., 2010; Radzyminska et al., 2014). Materials science laboratory or test stands are also potentially dangerous because of a very high (Opydo et al., 2016; Klimecka-Tatar, 2017) or ultra-low temperature (Wlodarczyk et al., 2011), a high pressure (Dudek and Wlodarczyk, 2010), high forces (Ulewicz et al., 2014; Mazur and Mikova, 2016; Sygut et al., 2016; Mazur et al., 2018), aggressive reagents (Szabracki and Lipinski, 2014), a laser emission (Radek et al., 2018) or a nanoparticles dust hazard (Korzekwa et al., 2018). The same situation may be observed at mechanical test stands e.g. resonance vibrations (Ferdek and Kozien, 2013). In general, it can be noted that such situations should be identified during the analysis of processes in enterprises and laboratories, and appropriate action should be taken to improve safety (Kozien and Kozien, 2017; Maszke et al., 2018). If possible, real experiments and dangerous tests should be replaced with numerical simulations of flows (Domagala et al., 2018a; Domagala et al., 2018b), high pressure devices (Filo et al., 2018) or a high temperature effects (Osocha et al., 2004; Osocha, 2018) with application of the statistical methods (Goroshko et al., 2014; Goroshko and Royzman, 2015) and an appropriate estimation of the uncertainty (Dwornicka et al., 2017; Gadek-Moszczak, 2017; Pietraszek et al., 2017).

\section{ACKNOWLEDGMENT}

The authors would like to thank Mr. Jakub Link-Lenczowski from the Polish Aviation Museum for his help in the field of aviation as well as to thank Danfoss Poland for technical support in the field of drive control.

\section{REFERENCES}

Cierniak-Emerych, A., Kiełbus, A., Mazur, M., 2017. Aspects of work-product-process safety. SMJiP, Częstochowa, Poland, 47-49.

Colbert, E.J.M., Hutchinson, S., 2016. Intrusion detection in industrial control systems. Advances in Information Security, 66, 209-237.

Directive 2006/42/EC of the European Parliament and of the Council of 17 May 2006 on machinery, and amending Directive 95/16/EC (recast). Official Journal of the European Union, OJ L 157, 9.6.2006, 24-86.

Domagala, M., Momein, H., Domagala-Fabis, J., Filo, G., Kwiatkowski, D., 2018a, Simulation of Cavitation Erosion in a Hydraulic Valve. Mater. Res. Proc. 5, 1-6.

Domagala, M., Momeni, H., Domagala-Fabis, J., Filo, G., Krawczyk, M., 2018b, Simulation of Particle Erosion in a Hydraulic Valve. Mater. Res. Proc. 5, 17-24.

Dudek, A., Wlodarczyk, R., 2010. Structure and properties of bioceramics layers used for implant coatings. Solid State Phenom., 165, 31-36.

Dwornicka, R., Radek, N., Krawczyk, M., Osocha, P., Pobedza, J., 2017. The laser textured surfaces of the silicon carbide analyzed with the bootstrapped tribology 
model. Metal 2017: $26^{\text {th }}$ Int. Conf. Metallurgy and Materials, Ostrava, Tanger, 12521257.

Ferdek, U., Kozien, M.S., 2013. Simulation of application of FGM piezoelectric actuators for active reduction of beam vibrations. Acta Phys. Pol. A, 123, 10441047.

Filo, G., Lisowski, E., Domagala, M., Fabis-Domagala, J., Momeni, H., 2018. Modelling of pressure pulse generator with the use of a flow control valve and a fuzzy logic controller. MSM 2018: $14^{\text {th }}$ Int. Conf. Mechatronic Systems and Materials, Zakopane, Poland, AIP Conf. Proc., 2029, art. 020015.

Gadek-Moszczak, A., 2017. History of stereology. Image Anal. Stereol., 36, 151-152.

Ghorbani, W. Lu, M. Tavallaee, 2010. Network intrusion detection and prevention. Springer, 1-216.

Goroshko, A., Royzman, V., Bubulis, A., Juzenas, K., 2014. Methods for testing and optimizing composite ceramics-compound joints by solving inverse problems of mechanics. J. Vibroeng., 16, 2178-2187.

Goroshko, A., Royzman, V., 2015. Statistical methods for providing the stability of the solutions of inverse problems and their application to decrease rotor vibroactivity. Journal of Machinery Manufacture and Reliability, 44, 232-238.

Klimecka-Tatar, D., 2017. Variation of the morphology of the dental alloys structure under the effect of selected commercially available methods of thermal processing. Metal 2017: 26 ${ }^{\text {rd }}$ Int. Conf. Metallurgy and Materials, Ostrava, Tanger, 1806-1812.

Korzekwa, J., Gadek-Moszczak, A., Zubko, M., 2018. Influence of the size of nanoparticles on the microstructure of oxide coatings. Mater. Sci. 53, 709-716.

Kozien, E., Kozien, M.S., 2017. Interval analysis as a method of measurement of uncertainity in the check-list method applied to identification of stage phase of companies. $26^{\text {th }}$ Int. Sci. Conf. Economic and Social Development - Building Resilient Society: Economic and Social Development. Varazdin Development \& Entrepreneurship Agency, Varazdin, Croatia, 210-215.

Krawczyk, J., Sobczyk, A., Stryczek, J., Walczak, P., 2018. Tests of new methods of manufacturing elements for water hydraulics. Mater. Res. Proc., 5, 200-205.

Lisowski, E., Filo, G., 2017. Analysis of a proportional control valve flow coefficient with the usage of a CFD method. Flow Meas Instrum 53, 269-278.

Lynn, P.A., 1986. Radar Systems. Springer, 1-146.

Maszke, A., Dwornicka, R., Ulewicz, R., 2018, Problems in the implementation of the lean concept at a steel works - case study. MATEC Web Conf., 183, art. 01014.

Mazur, M., Mikova, K., 2016. Impact resistance of high strength steels. Mater. TodayProc. 3, 1060-1063.

Mazur, M., Kucharikova, L., Tillova, E., Chalupova, M., 2018. A change of mechanical properties of the self-hardening UNIFONT 90 due to temperature. Mater. Res. Proc., 5, 136-141.

Misra, S., Maheswaren, M., Hashmi, S., 2017. Security challenges and approaches in internet of things. SpringerBriefs in Electrical and Computer Engineering, 5-52.

Opydo, M., Kobylecki, R., Dudek, A., Bis, Z., 2016. The effect of biomass cocombustion in a CFB boiler on solids accumulation on surfaces of P91 steel tube samples. Biomass \& Bioenergy 85, 61-68.

Osocha, P., Duda, P., Weglowski, B., 2004. Determining temperature and stress changes in thick-walled elements of steam lines. Inz. Chem. Procesowa 25, 22492256. 
Osocha, P., 2018. Calculation of residual life for P91 material based on creep rate and time to rupture. Mater. Res. Proc. 5, 177-182.

Pietraszek, J., Dwornicka, R., Krawczyk, M., Kołomycki, M., 2017. The nonparametric approach to the quantification of the uncertainty in the design of experiments modelling. UNCECOMP 2017, NTU of Athens, 598-604.

Radek, N., Szczotok, A., Gadek-Moszczak, A., Dwornicka, R., Broncek, J., Pietraszek, J., 2018. The impact of laser processing parameters on the properties of electro-spark deposited coatings. Arch. Metall. Mater., 63, 809-816.

Radzyminska-Lenarcik, E., Ulewicz, M., 2014. The use of 1-alkylimidzoles for selective separation of zinc ions in the transport process across a polymeric inclusion membrane. Physicochem. Probl. Mi. 50, 131-142.

Singh, B. et al., 2016a. Feasibility studies of time-like proton electromagnetic form factors at PANDA at FAIR. Eur. Phys. J. A, 52, art. 325.

Singh, B. et al., 2016b. Study of doubly strange systems using stored antiprotons. Nucl. Phys. A, 954, 323-340.

Singh, B. et al., 2017. Feasibility study for the measurement of pi $N$ transition distribution amplitudes at (P)over-barANDA in (P)over-barp $->\mathrm{J} /$ psi pi(0). Phys. Rev. D., 95(3), 25 p., art. 032003.

Skrzypczak-Pietraszek, E., Pietraszek, J., 2009. Phenolic acids in in vitro cultures of Exacum affine Balf. $f$. Acta Biol. Cracov. Bot., 51, 62-62.

Skrzypczak-Pietraszek, E., Piska, K., Pietraszek, J., 2018. Enhanced production of the pharmaceutically important polyphenolic compounds in Vitex agnus castus $L$. shoot cultures by precursor feeding strategy. Eng. Life Sci., 18, 287-297.

Sygut, P., Klimecka-Tatar, D., Borkowski, S., 2016. Theoretical analysis of the influence of longitudinal stress changes on band dimensions during continuous rolling process. Arch. Metall. Mater., 61, 183-188.

Szabracki, P., Lipinski, T., 2014. Influence of sigma phase precipitation on the intergranular corrosion resistance of X2CrNiMoN25-7-4 super duplex stainless steel. Metal 2014: $23^{\text {rd }}$ Int. Conf. Metallurgy and Materials 476-481.

Ulewicz, M., Walkowiak, W., Jang, Y.C., Kim, J.S., Bartsch, R.A., 2003. Ion flotation of cadmium(II) and zinc(II) in the presence of proton-ionizable lariat ethers. Anal. Chem., 75, 2276-2279.

Ulewicz, M., Sadowska, K., Biernat, J.F., (2007). Selective transport of $\mathrm{Pb}(\mathrm{II})$ across polymer inclusion membrane using imidazole azocrown ethers as carriers. Physicochem. Probl. Mi., 41, 133-143.

Ulewicz, M., Lesinska, U., Bochenska, M., 2010. Transport of lead across polymer inclusion membrane with p-tert-butylcalix[4]arene derivative. Physicochem. Probl. Miner. Process., 44(1), 245-256.

Ulewicz, R., Szataniak, P., Novy, F., 2014. Fatigue properties of wear resistant martensitic steel. Metal 2014: $23^{\text {rd }}$ Int. Conf. Metallurgy and Materials, Ostrava, Tanger, 784-789.

U.S. Access Board, 2015. Information and Communication Technology (ICT) Standards and Guidelines, Notice of Proposed Rulemaking, 36 CFR Parts 1193\&1194, United States Access Board.

Wlodarczyk, R., Dudek, A., Nitkiewicz, Z., 2011. Corrosion analysis of sintered material used for low-temperature fuel cell plates. Arch. Metall. Mater. 56, 181-186. 